Research Paper

\title{
Double-edged role of radiotherapy in patients with pulmonary large-cell neuroendocrine carcinoma
}

\author{
Yuanzhu Jiang1*, Cong Lei2*, Xufeng Zhang4, Yangang Cui², Keying Che², Hongchang Shen ${ }^{2,3, 凹}$ \\ 1. Department of Thoracic Surgery, Shandong Provincial Hospital Affiliated to Shandong University, 324 Jingwu Road, Jinan, 250021, P.R. China \\ 2. Department of Oncology, Shandong Provincial Hospital Affiliated to Shandong University, 324 Jingwu Road, Jinan, 250021, P.R. China \\ 3. Institute of Oncology, Shandong Provincial Hospital Affiliated to Shandong University, 324 Jingwu Road, Jinan, 250021, P.R. China \\ 4. Department of kidney Transplantation, Second Hospital of Shandong University, 247 Beiyuan Road, Jinan, 250000, P.R. China \\ *These authors contributed equally. \\ $\square$ Corresponding author: Hongchang Shen, 324 Jingwu Road, Jinan, 250021 P.R. China; Fax: +86-0531-68777921; E-mail: shc11312@163.com \\ () The author(s). This is an open access article distributed under the terms of the Creative Commons Attribution License (https://creativecommons.org/licenses/by/4.0/). \\ See http://ivyspring.com/terms for full terms and conditions.
}

Received: 2019.06.02; Accepted: 2019.09.19; Published: 2019.10.19

\begin{abstract}
Purpose: Pulmonary large-cell neuroendocrine carcinoma (LCNEC) is classified as non-small-cell lung cancer, but has characteristics similar to small-cell lung cancer. This study was performed to evaluate the effect of surgery and radiotherapy on patients with LCNEC.

Materials and Methods: We analyzed 1,619 patients with stage I-III LCNEC, identified from the Surveillance, Epidemiology, and End Results database, diagnosed from 2000 to 2013. The Kaplan-Meier analysis and the Cox proportional hazard model were used to study patient prognosis.

Results: Overall, 869 (53.7\%) stage I LCNEC patients, 203 (12.5\%) stage Il patients, and 547 (33.8\%) stage III patients were included in the analysis. Various surgery types were all associated with higher overall survival (OS) and lung cancer-specific survival (LCSS) than no surgery, with the following HRs: 0.334 (OS) and 0.279 (LCSS) for lobectomy, 0.468 (OS) and 0.416 (LCSS) for partial/wedge/segmental resection, and 0.593 (OS) and 0.522 (LCSS) for pneumonectomy (all $\mathrm{p}<$ 0.05 ). OS and LCSS of stage I and II LCNEC patients were not improved by radiotherapy (stage I: OS $p=0.719$, LCSS $p=0.557$; stage II: OS $p=0.136$, LCSS $p=0.697$ ). However, in stage III patients, radiotherapy significantly improved both OS and LCSS $(p<0.001)$. Following multivariate analysis, increased age, male patients, radiotherapy and diagnosed at stage II or III were all independent risk factors for LCNEC (all $\mathrm{p}<0.05$ ).

Conclusion: Lobectomy had the best outcome for OS and LCSS in stage I-II LCNEC. For stage III LCNEC patients, radiotherapy can significantly improve survival time. However, in LCNEC patients undergoing surgery, radiotherapy may reduce survival time.
\end{abstract}

Key words: pulmonary large-cell neuroendocrine carcinoma; surgery; radiotherapy; SEER

\section{Introduction}

Pulmonary neuroendocrine tumors originate from the endocrine cells of the lung and bronchial epithelium, accounting for $20 \%$ of primary lung cancers. Among them, pulmonary large-cell neuroendocrine carcinoma (LCNEC) accounts for 3\% $[1,2]$. LCNEC is pathologically classified as non-small-cell lung cancer (NSCLC), being regarded as a high-grade neuroendocrine tumor $[3,4]$. However, LCNEC shares several clinico-pathological characteristics with small-cell lung cancer (SCLC), including high degree of malignancy, poor patient prognosis, smoking-related disease and common neuroendocrine gene expression, which has attracted the attention of numerous scholars [5-7].

The diagnosis of LCNEC requires assessing both morphology and neuroendocrine differentiation by IHC [8-10]. In the current WHO classification, some of the features used to classify a tumor as LCNEC 
overlap with those applied for SCLC, NSCLC, and carcinoids [11]. As LCNEC is a very rare disease, difficult to diagnose and treat, only few data are available, and clinical trials are difficult to be performed. To date, optimal clinical management has not been established $[12,13]$. Surgery is generally the first choice for early-stage patients [14], as several studies have reported that LCNEC patients can benefit from early surgical interventions, achieving satisfactory results [15-18]. However, many people with pulmonary LCNEC have a high incidence of recurrence after surgery, even when performed for early-stage disease. There is evidence that chemotherapy is an effective method for preventing disease relapse [19-21]. Moreover, molecular subtypes of pulmonary LCNEC can predict the outcome of chemotherapy [22]. Nevertheless, data on radiotherapy in pulmonary LCNEC patients are limited [23, 24]. The role of radiotherapy in LCNEC remains unclear, and further research is necessary to establish its effectiveness [12].

To further investigate the influence of surgery and radiotherapy on prognosis and, in particular, to identify the optimal therapeutic method for patients with pulmonary LCNEC, we acquired data from the Surveillance, Epidemiology, and End Results (SEER) database and performed a retrospective analysis.

\section{Materials and Methods}

\section{Data Source and Ethical Regulations}

The SEER database is a National Cancer Institute (NCI) program, which encompasses information about cancer incidence and patient survival in the United States (SEER website [www.seer.cancer.gov]). Comprehensive data of diagnosed patients are included in the NCI SEER 18 Registries (SEER*Stat Database: Incidence-SEER 18 Regs Research Data + Hurricane Katrina Impacted Louisiana Cases, Nov 2015 Sub). The Institutional Review Board (IRB) approve this study. And an ethics committee is not required because individual patient data are de-identified.

\section{Study Population}

Our study sample consisted of 1,619 patients, with exfoliative cytologically and histologically confirmed American Joint Committee on Cancer (AJCC) stage I-III LCNEC, diagnosed from 2000 to 2013. The histology codes were identified according to International Classification of Diseases for Oncology (3rd Edition, ICD-O-3, 8013). Included patients were from SEER code 8013/3 (large-cell neuroendocrine carcinoma), and morphology site "lung and bronchus". Patients with undefined nodal status or M1 disease were excluded. In addition, we also excluded patients with unknown race, tumor size, surgery/surgery type, or survival months. Data of interest on therapeutic methods included type of surgery and radiotherapy administration. Chemotherapy details were not available. We assumed that almost all these patients received systemic therapy.

\section{Statistical Analyses}

The primary outcomes of this study were overall survival (OS) and lung cancer-specific survival (LCSS). OS and LCSS were analyzed using Cox regression. Kaplan-Meier analysis with the log-rank test was used to estimate OS and LCSS, and generate survival curves to compare patients who underwent surgery or received radiotherapy with those who did not [25]. Univariate analysis and multivariate analyses were carried out by the Cox proportional hazard model. Moreover, the multivariate Cox regression analysis included covariates that were significant in the univariate analysis, to determine which factors significantly influenced survival. A two-sided P-value $<0.05$ was considered statistically significant. All data were analyzed using the SPSS software package, version 20.0 (IBM, SPSS Statistics, Chicago, IL).

\section{Results}

\section{Patient characteristics}

We identified 1,619 patients with stage I-III LCNEC, diagnosed from 2000 to 2013. Patients' baseline demographic characteristics are presented in Table 1. There were $770(47.6 \%)$ female and 849 $(52.4 \%)$ male patients, with a median age of 67 years (18-94). Most patients were Caucasian (85.3\%) and married (85.7\%). Regarding treatment, 1020 patients underwent surgery only, 65 patients underwent radiotherapy only, 167 patients underwent surgery + radiotherapy, 138 those who had postoperative radiation therapy (PORT) and 367 those without such treatment. Of the patients who underwent lung resection, $850(52.5 \%)$ underwent lobectomy, 278 $(17.2 \%)$ underwent partial/wedge/segmental resection, and $56(3.4 \%)$ underwent pneumonectomy. Patients with stageILCNEC accounted for $53.7 \%$ of the total, stage II for $12.5 \%$, and stage III for $33.8 \%$.

\section{Effect of surgery on survival}

Results of the univariate Cox analysis of OS and LCSS are shown in Table 2. Survival analysis revealed that age, gender, surgery vs. no-surgery, and tumor-node-metastasis (TNM) stage were all significant factors for OS and LCSS. Survival time was significantly improved for patients with stage I to III LCNEC when undergoing surgical interventions (all $p$ $<0.001$; Figure 1). For OS, median survival time for all 
LCENC patients treated with surgery was 41.0 months (95\% CI, 34.9 to 47.1 months), which was significantly longer than that of patients who did not undergo surgery (12.0 months; $95 \% \mathrm{CI}, 10.3$ to 13.7 months). The median overall survival (OS) for surgically and non-surgically treated LCNEC patients was 69.0 months (95\% CI, 57.7 to 80.3 months) and 14.0 months (95\% CI, 9.7 to 18.3 months) in stage I, 23.0 months (95\% CI, 16.8 to 29.2 months) and 9.0 months (95\% CI, 6.7 to 11.3$)$ in stage II, and 17.0 months ( $95 \%$ CI, 13.4 to 20.6 months) and 12.0 months (95\% CI, 9.9 to 14.1 months) in stage III, respectively. For LCSS, median survival time for all LCENC patients treated with surgery was 78.0 months $(95 \%$ CI, 63.5 to 92.5 months), which was also significantly longer than that of patients without surgery (14.0 months; 95\% CI, 11.7 to 16.3 months). The median LCSS survival for surgically and non-surgically treated patients was 114.0 months $(95 \% \mathrm{CI}, 88.2$ to 139.8 months) 20.0 months (95\% CI, 13.8 to 26.2 months) in stage I, 32.0 months (95\%CI, 11.2 to 52.8 months) and 9.0 months ( $95 \% \mathrm{CI}, 7.6$ to 10.4 months) in stage II, and 25.0 months ( $95 \% \mathrm{CI}, 15.8$ to 34.2 months) and 14.0 months (95\% CI, 11.5 to 16.5 months) in stage III, respectively.

Various types of surgery were all associated with higher OS and LCSS than no surgery, with the following HRs: 0.334 (OS) and 0.279 (LCSS) for lobectomy, 0.468 (OS) and 0.416 (LCSS) for partial/wedge/segmental resection and 0.593 (OS) and 0.522 (LCSS) for pneumonectomy (all $\mathrm{p}<0.05$ ). Figure 2 shows the effect of multiple surgical interventions on survival. For OS, people who underwent lobectomy had the highest median survival time, of 51.0 months (95\% CI, 39.1 to 62.9 months), which was significant longer than that of patients without surgery (12.0 months; $95 \% \mathrm{CI}, 10.2$ to 13.8 months). Median overall survival time of patients who underwent partial/wedge/segmental resection was 29.0 months (95\% CI, 23.2 to 34.8 months), compared with pneumonectomy was 22.0 months (95\% CI, 11.5 to 32.5 months). For LCSS, people with lobectomy also had the best median survival, of 100.0 months (95\% CI, 77.0 to 123.0 months), whereas the median survival of patients without surgery was only 14.0 months (95\% CI, 11.8 to 16.2 months). Median survival time of patients who underwent partial/wedge/segmental resection and pneumonectomy was 42.0 months (95\% CI, 28.8 to 55.2 months) and 30.0 months (95\% CI, 14.8 to 45.2 months), respectively.

\section{Effect of radiotherapy on survival}

Figure 3 shows that OS and LCSS of stage I and II LCNEC patients were not improved by radiotherapy (stage I: OS $p=0.719$, LCSS $p=0.557$; stage II: OS $p=$ 0.136 , LCSS $p=0.697$ ). However, in stage III patients, radiotherapy significantly improved both OS and LCSS ( $p<0.001)$.

Table 1. Characteristics of Patients with Stage I to III Large-Cell Neuroendocrine Carcinoma $(n=1,619)$

\begin{tabular}{|c|c|}
\hline Characteristics & No. $(\%)$ \\
\hline \multicolumn{2}{|l|}{ Age(years) } \\
\hline$<65$ & 633(39.1) \\
\hline$\geq 65$ & $986(60.9)$ \\
\hline \multicolumn{2}{|l|}{ Gender } \\
\hline Female & $770(47.6)$ \\
\hline Male & $849(52.4)$ \\
\hline \multicolumn{2}{|l|}{ Race } \\
\hline White & $1381(85.3)$ \\
\hline Black & 177(10.9) \\
\hline Other & $61(3.8)$ \\
\hline \multicolumn{2}{|l|}{ Marital status } \\
\hline Married & $1387(85.7)$ \\
\hline Unmarried & 173(10.7) \\
\hline Unknown & $59(3.6)$ \\
\hline \multicolumn{2}{|l|}{ CHSDA region } \\
\hline East & $855(52.8)$ \\
\hline Nothern Plains & $154(9.5)$ \\
\hline Pacific Coast & $566(35.0)$ \\
\hline Southwest & $44(2.7)$ \\
\hline \multicolumn{2}{|l|}{ Primary site } \\
\hline Upper lobe & $1005(62.1)$ \\
\hline Middle lobe & $92(5.7)$ \\
\hline Lower lobe & $442(27.3)$ \\
\hline Main bronchus & $24(1.5)$ \\
\hline Other & $56(3.4)$ \\
\hline \multicolumn{2}{|l|}{ Surgery } \\
\hline No surgery & $435(26.9)$ \\
\hline Lobectomy & $850(52.5)$ \\
\hline Partial/wedge/segmental resection & $278(17.2)$ \\
\hline Pneumonectomy & $56(3.4)$ \\
\hline \multicolumn{2}{|l|}{ Radiotherapy } \\
\hline Yes & 1387(85.7) \\
\hline No & $232(14.3)$ \\
\hline \multicolumn{2}{|l|}{ TNM stage } \\
\hline Stage I & $869(53.7)$ \\
\hline Stage II & 203(12.5) \\
\hline Stage III & $547(33.8)$ \\
\hline \multicolumn{2}{|l|}{ Grade } \\
\hline Well differentiated; Grade I & $8(0.5)$ \\
\hline Moderately differentiated; Grade II & $37(2.3)$ \\
\hline Poorly differentiated; Grade III & $771(47.6)$ \\
\hline Undifferentiated; anaplastic; Grade IV & $230(14.2)$ \\
\hline Unknown & $573(35.4)$ \\
\hline \multicolumn{2}{|c|}{ No. of nodes examined in surgery (surgery $n=1,184$ ) } \\
\hline 0 & 132(11.1) \\
\hline $1-3$ & 206(17.4) \\
\hline $4-10$ & $429(36.2)$ \\
\hline $10+$ & $286(24.2)$ \\
\hline Unknown & 131(11.1) \\
\hline \multicolumn{2}{|c|}{ No. of nodes positive in surgery (surgery $n=1,184$ ) } \\
\hline 0 & $772(65.2)$ \\
\hline $1-3$ & 211(17.8) \\
\hline $4-10$ & $40(3.4)$ \\
\hline $10+$ & $6(0.5)$ \\
\hline Unknown & 155(13.1) \\
\hline
\end{tabular}


When surgery was performed, the use of radiation was associated with a shorter median survival time (OS: 27 vs. 44 months, $\mathrm{p}=0.012$; LCSS: 37 vs. 93 months, $\mathrm{p}<0.001)$. In contrast, longer median survival time was found with the use of radiation when surgery was not performed (OS: 25 vs.
11 months, $\mathrm{p}<0.001$; LCSS: 34 vs. 12 months, $\mathrm{p}<$ 0.001) (Figure 4). Compared to patients who underwent postoperative radiotherapy, patients with surgery alone had a longer survival time (OS: 44 vs. 30 months, $\mathrm{p}=0.024$; LCSS: 93 vs. 38 months, $\mathrm{p}<0.001$ ) (Figure 5).

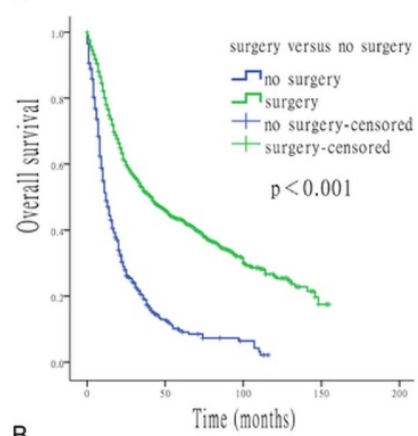

B

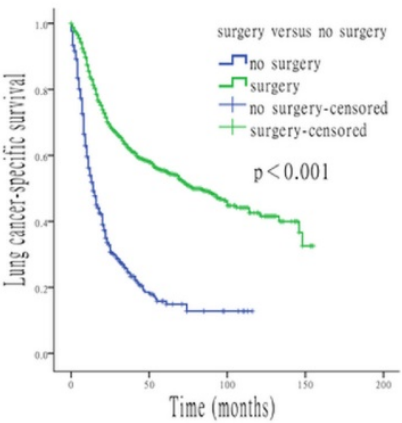

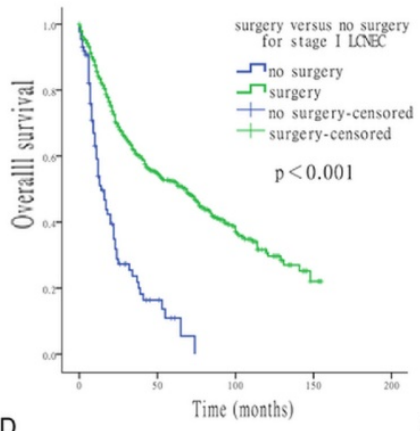

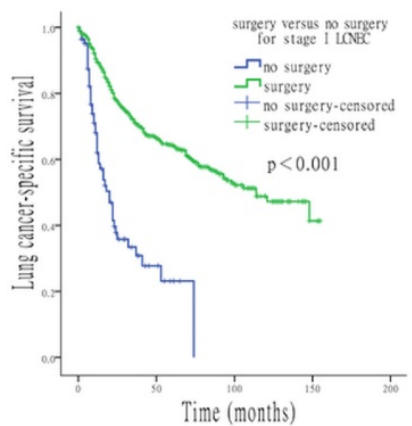

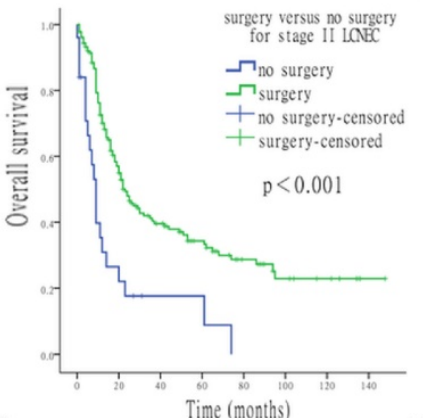

$\mathrm{F}$

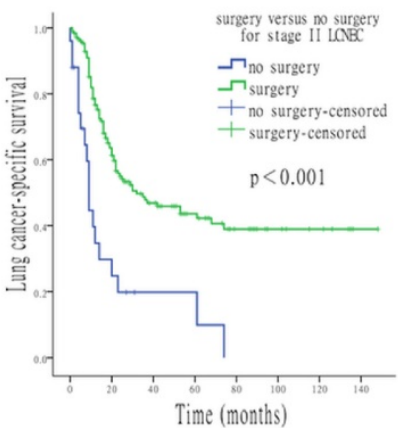

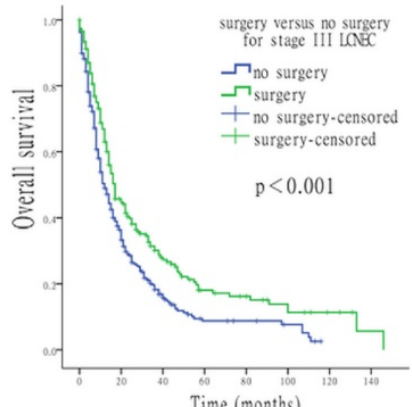

$\mathrm{H}$

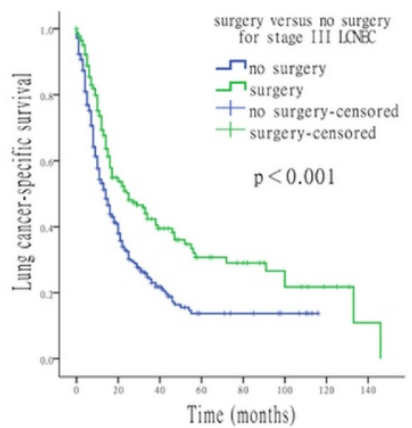

Figure 1. Survival analysis for OS and LCSS based on surgery or no-surgery, at each stage of LCNEC. (A) OS of patients treated with or without surgery. (B) LCSS of patients treated with or without surgery. (C) OS of stage I LCNEC patients, treated with or without surgery. (D) LCSS of stage I LCNEC patients, treated with or without surgery. (E) OS of stage II LCNEC patients, treated with or without surgery. (F) LCSS of stage II LCNEC patients, treated with or without surgery. (G) OS of stage III LCNEC patients, treated with or without surgery. $(\mathrm{H})$ LCSS of stage III LCNEC patients, treated with or without surgery.

A

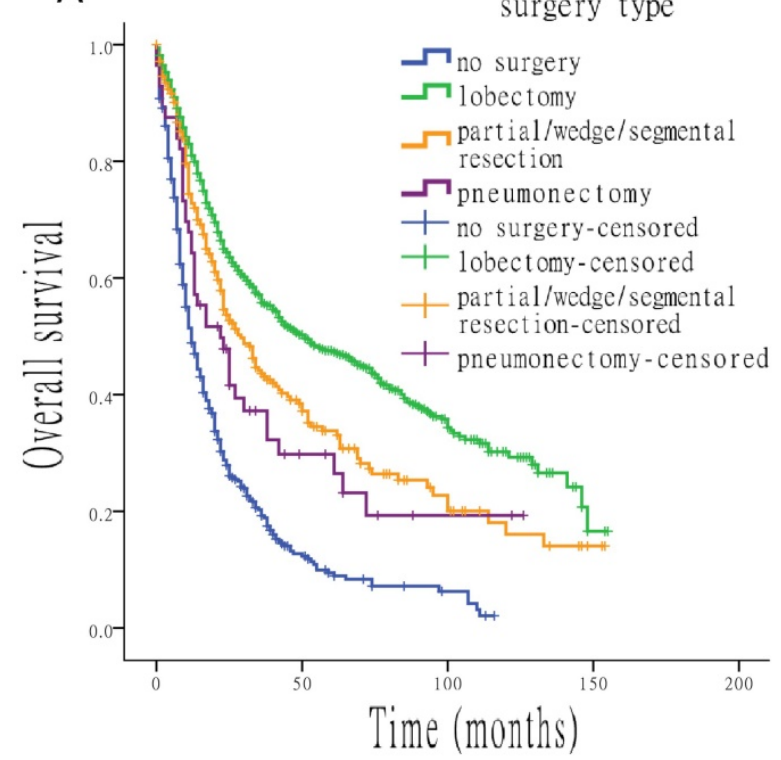

B

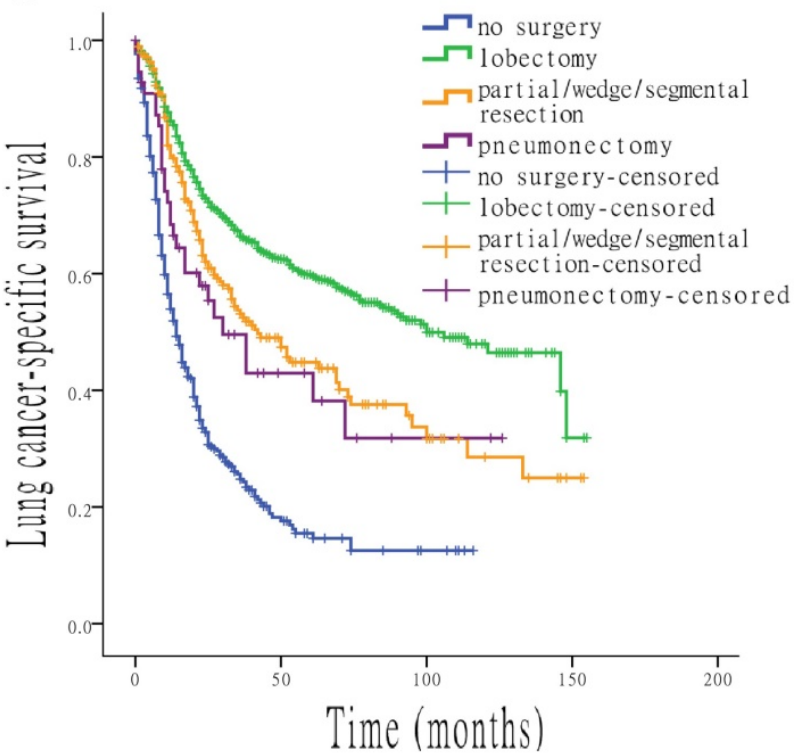

Figure 2. Survival analysis for OS and LCSS based on type of surgery. (A) OS of all patients, treated with different types of surgery. (B) LCSS of all patients, treated with different types of surgery. 

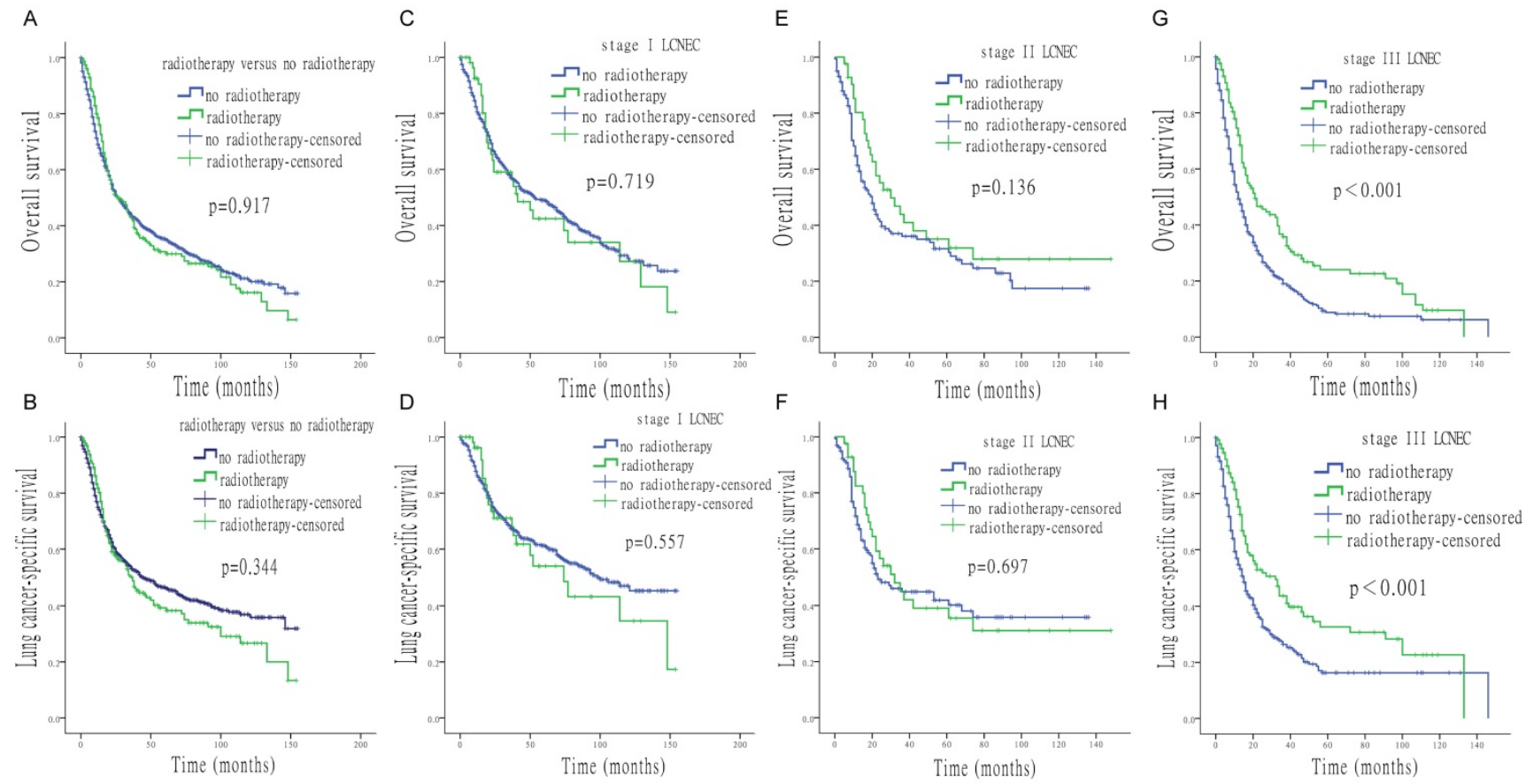

Figure 3. Survival analysis for OS and LCSS based on radiotherapy or no-radiotherapy, at each stage of LCNEC. (A) OS of patients treated with or without radiotherapy. (B) LCSS of patients treated with or without radiotherapy. (C) OS of stage I LCNEC patients, treated with or without radiotherapy. (D) LCSS of stage I LCNEC patients, treated with or without radiotherapy. (E) OS of stage II LCNEC patients, treated with or without radiotherapy. (F) LCSS of stage II LCNEC patients, treated with or without radiotherapy. (G) OS of stage III LCNEC patients, treated with or without radiotherapy. (H) LCSS of stage III LCNEC patients, treated with or without radiotherapy.

A

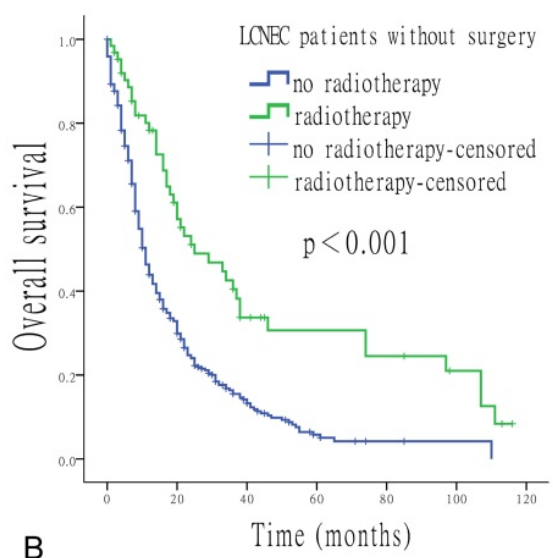

B

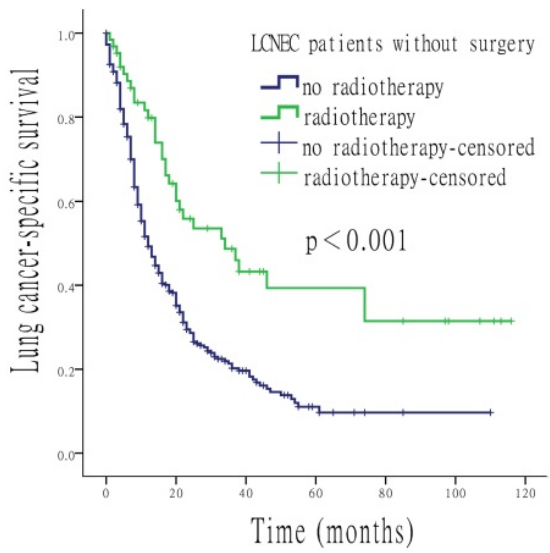

C
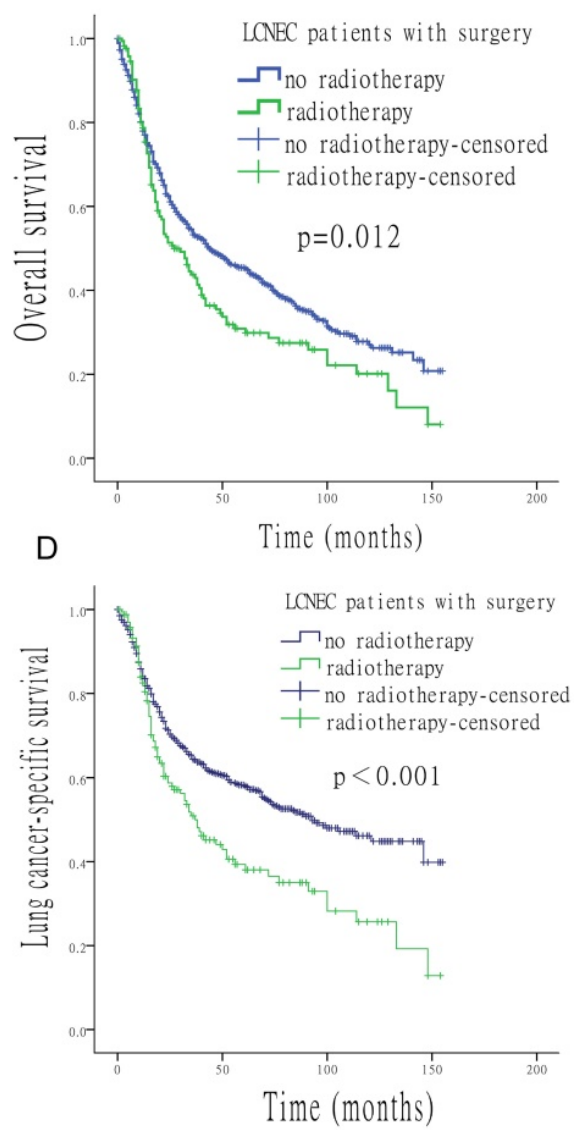

Figure 4. Survival analysis for OS and LCSS relative to surgery and radiotherapy. (A) OS of patients who did not undergo surgery, treated with or without radiotherapy. (B) LCSS of patients who did not undergo surgery, treated with or without radiotherapy. (C) OS of patients who underwent surgery, with the addition or in the absence of radiotherapy. (D) LCSS of patients underwent surgery, with the addition or in the absence of radiotherapy. 
Table 2. Univariate Analysis for Large-Cell Neuroendocrine Carcinoma Using Cox Proportional Hazards Model $(n=1,619)$

\begin{tabular}{|c|c|c|c|c|}
\hline & OS & & LCSS & \\
\hline Variable & $\mathrm{HR}(95 \% \mathrm{CI})$ & P value & $\mathrm{HR}(95 \% \mathrm{CI})$ & $\mathrm{P}$ value \\
\hline \multicolumn{5}{|l|}{ Age(years) } \\
\hline \multicolumn{5}{|l|}{$<65$} \\
\hline$\geq 65$ & $1.552(1.359-1.773)$ & $<0.001$ & $1.458(1.251-1.699)$ & $<0.001$ \\
\hline \multicolumn{5}{|l|}{ Gender } \\
\hline \multicolumn{5}{|l|}{ Female } \\
\hline Male & $1.210(1.067-1.372)$ & 0.003 & $1.213(1.048-1.403)$ & 0.010 \\
\hline \multicolumn{5}{|l|}{ Race } \\
\hline \multicolumn{5}{|l|}{ White } \\
\hline Black & $0.991(0.807-1.217)$ & 0.930 & $0.969(0.762-1.231)$ & 0.795 \\
\hline Other & $1.015(0.736-1.400)$ & 0.926 & $0.907(0.613-1.343)$ & 0.625 \\
\hline \multicolumn{5}{|l|}{ Marital status } \\
\hline \multicolumn{5}{|l|}{ Married } \\
\hline Unmarried & $1.076(0.875-1.323)$ & 0.487 & $1.041(0.817-1.327)$ & 0.746 \\
\hline Unknown & $1.036(0.728-1.475)$ & 0.845 & $0.976(0.644-1.481)$ & 0.911 \\
\hline \multicolumn{5}{|l|}{ CHSDA region } \\
\hline \multicolumn{5}{|l|}{ East } \\
\hline Nothern Plains & $1.008(0.807-1.259)$ & 0.944 & $0.953(0.734-1.237)$ & 0.716 \\
\hline Pacific Coast & $1.048(0.915-1.201)$ & 0.496 & $0.995(0.848-1.166)$ & 0.947 \\
\hline Southwest & $1.318(0.912-1.905)$ & 0.142 & $1.494(1.004-2.223)$ & 0.048 \\
\hline \multicolumn{5}{|l|}{ Primary site } \\
\hline \multicolumn{5}{|l|}{ Upper lobe } \\
\hline Middle lobe & $1.155(0.894-1.493)$ & 0.271 & $1.139(0.843-1.540)$ & 0.396 \\
\hline Lower lobe & $1.124(0.973-1.297)$ & 0.111 & $1.135(0.962-1.339)$ & 0.135 \\
\hline Main bronchus & $1.764(1.141-2.727)$ & 0.011 & $1.832(1.112-3.019)$ & 0.017 \\
\hline Other & $1.492(1.074-2.072)$ & 0.017 & $1.283(0.851-1.937)$ & 0.234 \\
\hline \multicolumn{5}{|l|}{ Surgery } \\
\hline \multicolumn{5}{|l|}{ No surgery } \\
\hline Lobectomy & $0.334(0.289-0.386)$ & $<0.001$ & $0.279(0.236-0.329)$ & $<0.001$ \\
\hline Partial/wedge/segmental resection & $0.468(0.389-0.564)$ & $<0.001$ & $0.416(0.336-0.515)$ & $<0.001$ \\
\hline Pneumonectomy & $0.593(0.427-0.823)$ & 0.002 & $0.522(0.356-0.764)$ & 0.001 \\
\hline \multicolumn{5}{|l|}{ Radiotherapy } \\
\hline \multicolumn{5}{|l|}{ Yes } \\
\hline No & $1.009(0.848-1.200)$ & 0.918 & $1.098(0.903-1.336)$ & 0.349 \\
\hline \multicolumn{5}{|l|}{ TNM stage } \\
\hline \multicolumn{5}{|l|}{ Stage I } \\
\hline Stage II & $1.628(1.337-1.982)$ & $<0.001$ & $1.872(1.491-2.351)$ & $<0.001$ \\
\hline Stage III & $2.600(2.268-2.980)$ & $<0.001$ & $3.054(2.604-3.581)$ & $<0.001$ \\
\hline \multicolumn{5}{|l|}{ Grade } \\
\hline \multicolumn{5}{|l|}{ Well differentiated; Grade I } \\
\hline Moderately differentiated; Grade II & $1.219(0.421-3.525)$ & 0.715 & $1.171(0.341-4.021)$ & 0.802 \\
\hline Poorly differentiated; Grade III & $1.232(0.460-3.297)$ & 0.678 & $1.221(0.392-3.805)$ & 0.731 \\
\hline Undifferentiated; anaplastic; Grade IV & $1.276(0.472-3.451)$ & 0.631 & $1.271(0.403-4.012)$ & 0.682 \\
\hline Unknown & $1.668(0.623-4.466)$ & 0.309 & $1.684(0.540-5.253)$ & 0.369 \\
\hline
\end{tabular}
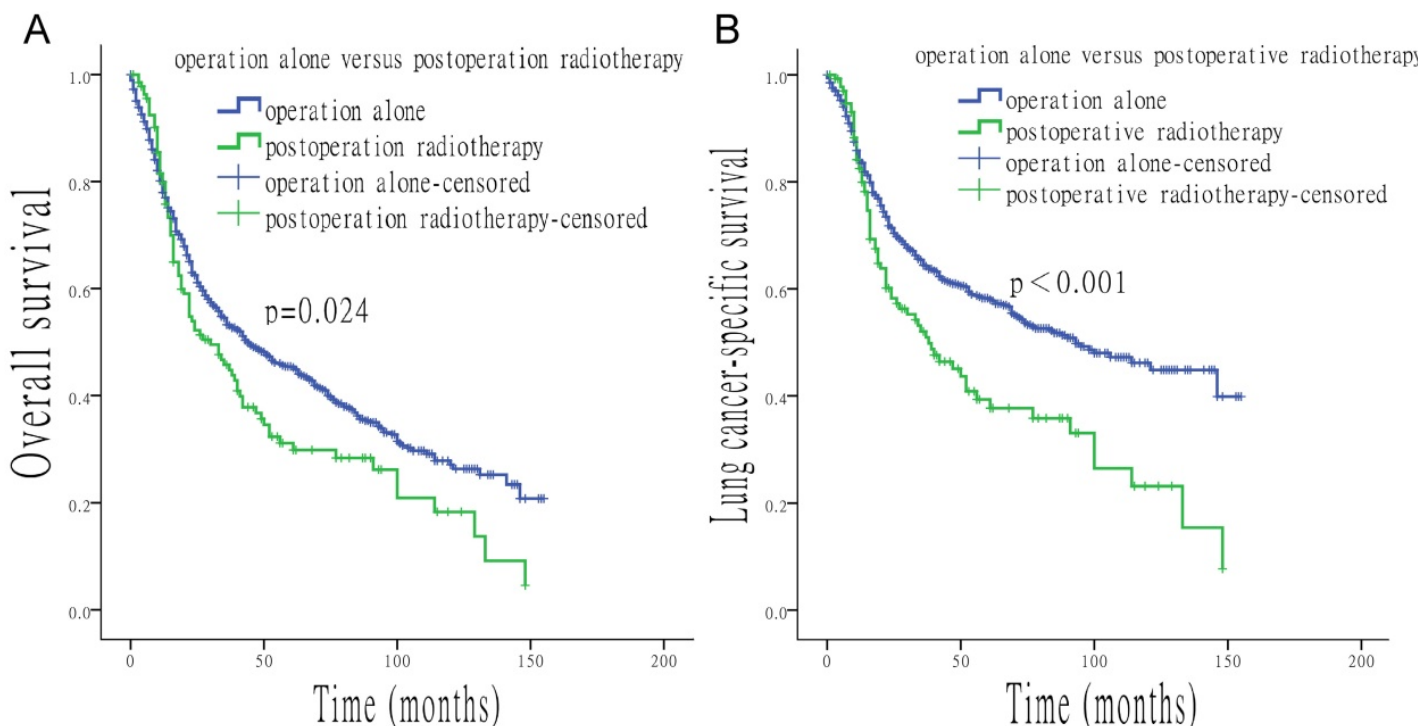

Figure 5: Survival analysis based on surgery alone, or with the addition of postoperative radiotherapy. (A) OS of patients treated with surgery alone, or with surgery and postoperative radiotherapy. (B) LCSS of patients treated with surgery alone, or with surgery and postoperative radiotherapy. 
Table 3. Multivariate Analysis for Large-Cell Neuroendocrine Carcinoma Using Cox Proportional Hazards Model $(n=1,619)$

\begin{tabular}{|c|c|c|c|c|}
\hline Variable & Overall survival & & Lung cancer-specific survival & \\
\hline & $\mathrm{HR}(95 \% \mathrm{CI})$ & P value & $\mathrm{HR}(95 \% \mathrm{CI})$ & P value \\
\hline \multicolumn{5}{|l|}{ Age(years) } \\
\hline \multicolumn{5}{|l|}{$<65$} \\
\hline$\geq 65$ & $1.564(1.365-1.793)$ & $<0.001$ & $1.491(1.273-1.745)$ & $<0.001$ \\
\hline \multicolumn{5}{|l|}{ Gender } \\
\hline \multicolumn{5}{|l|}{ Female } \\
\hline Male & 1.199 (1.056-1.362) & 0.005 & $1.212(1.046-1.406)$ & 0.011 \\
\hline \multicolumn{5}{|l|}{ Primary site } \\
\hline \multicolumn{5}{|l|}{ Upper lobe } \\
\hline Middle lobe & $1.211(0.936-1.567)$ & 0.145 & $1.216(0.899-1.645)$ & 0.205 \\
\hline Lower lobe & $1.065(0.920-1.233)$ & 0.397 & $1.091(0.921-1.293)$ & 0.311 \\
\hline Main bronchus & $1.120(0.717-1.750)$ & 0.619 & $1.069(0.642-1.779)$ & 0.799 \\
\hline Other & $0.797(0.568-1.118)$ & 0.189 & $0.633(0.416-0.965)$ & 0.033 \\
\hline \multicolumn{5}{|l|}{ Surgery } \\
\hline \multicolumn{5}{|l|}{ No surgery } \\
\hline Lobectomy & $0.464(0.389-0.554)$ & $<0.001$ & $0.394(0.321-0.482)$ & $<0.001$ \\
\hline Partial/wedge/segmental resection & $0.648(0.524-0.802)$ & $<0.001$ & $0.594(0.465-0.758)$ & $<0.001$ \\
\hline Pneumonectomy & $0.627(0.446-0.880)$ & 0.007 & $0.535(0.361-0.795)$ & 0.002 \\
\hline \multicolumn{5}{|l|}{ Radiotherapy } \\
\hline \multicolumn{5}{|l|}{ Yes } \\
\hline No & $0.765(0.637-0.920)$ & 0.004 & $0.809(0.658-0.995)$ & 0.045 \\
\hline \multicolumn{5}{|l|}{ TNM stage } \\
\hline \multicolumn{5}{|l|}{ Stage I } \\
\hline Stage II & 1.839 (1.499-2.256) & $<0.001$ & $2.099(1.657-2.657)$ & $<0.001$ \\
\hline Stage III & $2.060(1.735-2.444)$ & $<0.001$ & $2.238(1.833-2.733)$ & $<0.001$ \\
\hline
\end{tabular}

\section{Multivariate analysis on survival}

Table 3 shows that increased age, male patients, radiotherapy, and stage II or III at diagnosis, were all significant risk factors for LCNEC (all $\mathrm{p}<0.05$ ). Surgery was significantly associated with a favorable prognosis for LCNEC patients $(\mathrm{p}<0.05)$. Primary site was not a prognostic factor for LCNEC $(p>0.05)$.

\section{Discussion}

Through a large population-based cohort, we found that patients with pulmonary LCNEC who underwent surgery had significantly improved survival outcomes compared to non-surgicallytreated patients. Moreover, patients who underwent lobectomy had the best outcome, followed by those who underwent partial/wedge/segmental resection. Thus, surgical resection should be considered in the treatment of stage I-III LCNEC. As previously mentioned, pulmonary LCNEC shares some similar characteristics with SCLC, and chemotherapy and radiotherapy form the current standard treatment for patients with SCLC [26]. Consequently, we explored the role of radiotherapy in the treatment of LCNEC patients. We found that radiotherapy significantly improved survival time only in stage III LCNEC. Subsequently, we divided patients into two groups (surgery and no surgery). Patients in the no surgery group had better outcomes when undergoing radiotherapy. On the contrary, there was no survival benefit for LCNEC patients who underwent both surgery and radiotherapy. Meanwhile, compared to patients who underwent postoperative radiotherapy, patients with surgery alone had a longer survival time. Based on these results, radiotherapy could be applicable for patients unsuitable for surgery, especially for those with stage III LCNEC. However, for patients undergoing surgery, combination treatment with radiotherapy should be carefully considered. The multivariable analysis demonstrated that survival depended on age, gender, surgery, radiotherapy and TNM stage.

Recently, several studies support surgical resection for patients with early-stage LCNEC. For example, Zacharias et al. [16] found that patients treated via complete resection after systematic nodal dissection had longer survival time than previously described. Grand et al. [17] reported that surgical resection improved survival in about one third of patients. Roesel et al. [15] found that surgical treatment can achieve satisfactory results in early stages pulmonary LCNEC. The overall 1-, 3- and 5 -year survival rates for the surgery group were $83.7 \%, 63.2 \%$, and $53.8 \%$, respectively. Our findings are in agreement with these retrospective studies. Data on effectiveness of radiotherapy in pulmonary LCNEC are limited. Rieber et al. [23] conducted a retrospective analysis to investigate treatment outcome following multimodal treatment in 70 patients with LCNEC. In patients with incompletely resection and postoperative radiotherapy, 2- and 5 -year survival rates were 50 and $30 \%$, respectively. 
The authors concluded that the administration of radiotherapy contributes to acceptable results of multimodal treatment regimes. Prelaj et al. [24] showed that patients undergoing thoracic radiotherapy had higher mPFS and mOS (12.5 vs. 5 months, $\mathrm{p}=0.02$ and 28.3 vs. 5 months, $\mathrm{p}=0.004$ ). Nevertheless, further research is needed to assess the effectiveness of radiotherapy in patients with pulmonary LCNEC.

In this study, data on chemotherapy were not accessed. However, many authors support the use of chemotherapy in LCNEC patients. In a prospective study, Iyoda et al. [21] observed that adjuvant chemotherapy, consisting of cisplatin and VP-16, administered post-surgery, improved the prognosis of LCNEC patients. Christopoulos et al. [19] conducted a multicenter phase II trial, and found that everolimus in combination with carboplatin and paclitaxel was an effective first-line treatment for patients with stage IV LCNEC. Derks et al. [27] thought that NSCLC-t chemotherapy (median survival: 8.5 months) resulted in a better prognosis compared to NSCLC-pt (median survival: 5.9 months) and SCLC-t (median survival: 6.7 months) chemotherapy. These studies showed that chemotherapy is paramount for effective treatment.

The present retrospective study has some limitations. On the one hand, several clinical data were not available in the SEER database. For example, low grade (G1/G2) "LCNEC" and carcinoma with unknown Grading were not excluded, due to the limitation of SEER database. Specifically, we were unable to obtain chemotherapy data, which is important for prognosis evaluation. In addition, information about scope and dose of radiation was also lacking. Lastly, we could not evaluate positive or negative surgical margins. On the other hand, inherent selection bias is inevitable in a retrospective study.

\section{Conclusions}

LCNEC is an aggressive and rare tumor, with generally poor prognosis. Nevertheless, our results indicate that Lobectomy seems to be the optimal treatment for patients with LCNEC in the early stages (I-II). For stage III LCNEC patients, radiotherapy could potentially have a positive effect on survival time, especially for patients unsuitable for surgical resection. However, we do not recommend the use of radiotherapy in patients undergoing surgery, based on our results, it may reduce survival time.

\section{Abbreviations}

AJCC: American Joint Committee on Cancer; LCNEC: large-cell neuroendocrine carcinoma; LCSS: lung cancer-specific survival; NSCLC: non-small-cell lung cancer; NCI: National Cancer Institute; OS: overall survival; SCLC: small-cell lung cancer; SEER: Surveillance, Epidemiology, and End Results; IRB: Institutional Review Board; TNM: tumor-nodemetastasis.

\section{Acknowledgements}

The work was supported by Key Research and Development Plan of Shandong Province [grant numbers 2015GSF118109, 2015GSF118063] , Shandong Provincial Natural Science Foundation [grant number ZR2017PH058, ZR2018BH027, ZR2019MH026] , Jinan Clinical Medical Science and Technology Innovation Plan [grant number 201821078], Shandong Key research and development Program [grant number 2017GSF218110, 2016GSF201145] and National Natural Science Foundation of China [grant number 81672288].

\section{Ethics approval and consent to participate}

Comprehensive data of diagnosed patients are included in the NCI SEER 18 Registries (SEER*Stat Database: Incidence-SEER 18 Regs Research Data + Hurricane Katrina Impacted Louisiana Cases, Nov 2015 Sub). The Institutional Review Board (IRB) approves this study. And an ethics committee is not required because individual patient data are de-identified.

\section{Availability of data and materials}

The datasets generated and/or analysed during the current study are available in the [Surveillance, Epidemiology, and End Results database], [https://seer.cancer.gov/data/].

\section{Authors' contributions}

YZJ and HCS conceived and designed the study. LC, YGC and XFZ collected clinical data and performed the statistical analysis. LC, XFZ and KYC performed the research and wrote the paper. All authors read and approved the final manuscript.

\section{Competing Interests}

The authors have declared that no competing interest exists.

\section{References}

1. Derks JL, Hendriks LE, Buikhuisen WA, Groen HJ, Thunnissen E, van Suylen RJ, Houben R, Damhuis RA, Speel EJ, Dingemans AM. Clinical features of large cell neuroendocrine carcinoma: a population-based overview. Eur Respir J. 2016; 47:615-624.

2. Oberg K, Castellano D. Current knowledge on diagnosis and staging of neuroendocrine tumors. Cancer Metastasis Rev 2011; 30 Suppl 1:3-7.

3. Gollard R, Jhatakia S, Elliott M, Kosty M. Large cell/neuroendocrine carcinoma. Lung Cancer. 2010; 69:13-18.

4. Iyoda A, Makino T, Koezuka S, Otsuka H, Hata Y: Treatment options for patients with large cell neuroendocrine carcinoma of the lung. Gen Thorac Cardiovasc Surg. 2014; 62:351-356. 
5. Travis WD, Gal AA, Colby TV, Klimstra DS, Falk R, Koss MN. Reproducibility of neuroendocrine lung tumor classification. Hum Pathol. 1998; 29:272-279.

6. Travis WD, Rush W, Flieder DB, Falk R, Fleming MV, Gal AA, Koss MN. Survival analysis of 200 pulmonary neuroendocrine tumors with clarification of criteria for atypical carcinoid and its separation from typical carcinoid. Am J Surg Pathol. 1998; 22:934-944.

7. Rekhtman N, Pietanza MC, Hellmann MD, Naidoo J, Arora A, Won $\mathrm{H}$ Halpenny DF, Wang H, Tian SK, Litvak AM, et al. Next-Generation Sequencing of Pulmonary Large Cell Neuroendocrine Carcinoma Reveals Small Cell Carcinoma-like and Non-Small Cell Carcinoma-like Subsets. Clin Cancer Res. 2016; 22:3618-3629.

8. Travis WD, Garg K, Franklin WA, Wistuba II, Sabloff B, Noguchi M, Kakinuma R, Zakowski M, Ginsberg M, Padera R, Jacobson F, Johnson BE, Hirsch F, Brambilla E, Flieder DB, Geisinger KR, Thunnissen F, Kerr K, Yankelevitz D, Franks TJ, Galvin JR, Henderson DW, Nicholson AG, Hasleton PS, Roggli V, Tsao MS, Cappuzzo F, Vazquez M. Bronchioloalveolar carcinoma and lung adenocarcinoma: the clinical importance and research relevance of the 2004 World Health Organization pathologic criteria. J Thorac Oncol. 2006;1(9 Suppl):13-9.

9. Travis WD, Brambilla E, Burke AP, Marx A, Nicholson AG. WHO Classification of Tumours of the Lung, Pleura, Thymus and Heart. Fourth edition. In: WHO Classification of Tumours. Geneva, Switzerland: World Health Organization. 2015.

10. Travis WD, Brambilla E, Nicholson AG, Yatabe $Y$, Austin JHM, Beasley MB, Chirieac LR, Dacic S, Duhig E, Flieder DB, Geisinger K, Hirsch FR, Ishikawa Y,Kerr KM, Noguchi M, Pelosi G, Powell CA, Tsao MS, Wistuba I. WHO Panel. The 2015 World Health Organization Classification of Lung Tumors: Impact of Genetic,Clinical and Radiologic Advances Since the 2004 Classification. J Thorac Oncol. 2015; 10(9):1243-1260.

11. Thunnissen E, et al. Russell Prudence, den Bakker Michael, Botling Johan, Brambilla Elisabeth, De Cuba Erienne, R Geisinger Kim, Hiroshima Kenzo, Marchevsky Alberto, Minami Yuko, Moreira Andre, G. Nicholson Andrew, Noguchi Masayuki: The use of immunohistochemistry improves the diagnosis of small cell lung cancer and its differential diagnosis. An international reproducibility study in a demanding set of cases. J Thorac Oncol. 2017;12:334-46.

12. Fasano M, Della Corte CM, Papaccio F, Ciardiello F, Morgillo F. Pulmonary Large-Cell Neuroendocrine Carcinoma: From Epidemiology to Therapy. J Thorac Oncol 2015; 10:1133-1141.

13. Lo RG, Pusceddu S, Proto C, Macerelli M, Signorelli D, Vitali Milena, Ganzinelli Monica, Gallucci Rosaria, Zilembo Nicoletta, Platania Marco, Buzzoni Roberto, de Braud Filippo, Garassino Marina. Treatment of lung large cell neuroendocrine carcinoma. Tumour biology: the journal of the International Society for Oncodevelopmental Biology and Medicine. 2016; 37:7047-7057.

14. Ramirez RA, Chauhan A, Gimenez J, Thomas KEH, Kokodis I, Voros BA. Management of pulmonary neuroendocrine tumors. Rev Endocr Metab Disord. 2017.

15. Roesel C, Terjung S, Weinreich G, Gauler T, Theegarten D, Stamatis G, Welter S. A Single-Institution Analysis of the Surgical Management of Pulmonary Large Cell Neuroendocrine Carcinomas. Ann Thorac Surg 2016; 101:1909-1914.

16. Zacharias J, Nicholson AG, Ladas GP, Goldstraw P. Large cell neuroendocrine carcinoma and large cell carcinomas with neuroendocrine morphology of the lung: prognosis after complete resection and systematic nodal dissection. Ann Thorac Surg 2003; 75:348-352.

17. Grand B, Cazes A, Mordant P, Foucault C, Dujon A, Guillevin EF, Barthes Fle $P$, Riquet $M$. High grade neuroendocrine lung tumors: pathological characteristics, surgical management and prognostic implications. Lung Cancer. 2013; 81:404-409.

18. Fournel L, Falcoz PE, Alifano M, Charpentier MC, Boudaya MS, Magdeleinat P, Damotte D, Regnard JF. Surgical management of pulmonary large cell neuroendocrine carcinomas: a 10-year experience. Eur J Cardiothorac Surg. 2013; 43:111-114

19. Christopoulos P, Engel-Riedel W, Grohé C, Kropf-Sanchen Cornelia, Pawel Joachim, Gütz S, Kollmeier Jens, Eberhardt Wilfried, Ukena D, Baum V, Nimmrich I, Sieder C, Schnabel Philipp, Serke Monika, Thomas M. Everolimus with paclitaxel and carboplatin as first-line treatment for metastatic large-cell neuroendocrine lung carcinoma: A multicenter phase II trial. Annals of oncology : official journal of the European Society for Medical Oncology. 2017, 28:1898-1902.

20. Veronesi Giulia, Morandi Uliano, Alloisio Marco, Terzi Alberto, Cardillo Giuseppe, Filosso Pierluigi, Rea Federico, Facciolo Francesco, Pelosi Giuseppe, Gandini Sara, Calabrò Francesco, Casali C, Marulli Giuseppe, Spaggiari L. Large cell neuroendocrine carcinoma of the lung: a retrospective analysis of 144 surgical cases. Lung Cancer 2006, 53:111-115.

21. Iyoda A, Hiroshima K, Moriya Y, Takiguchi Y, Sekine Y, Shibuya K, Iizasa T, Kimura H, Nakatani $Y$, Fujisawa T. Prospective study of adjuvant chemotherapy for pulmonary large cell neuroendocrine carcinoma. Ann Thorac Surg. 2006; 82:1802-1807.

22. Derks, Jules \& Leblay, Noémie \& Thunnissen, Erik \& Jan van Suylen, Robert \& den Bakker, Michael \& JM Groen, Harry \& Smit, Egbert \& Damhuis, Ronald \& C van den Broek, Esther \& Chabrier, Amelie \& Foll, Matthieu \& Mckay, James \& Fernández-Cuesta, Lynnette \& M. Speel, Ernst-Jan \& Dingemans, Anne-Marie: Molecular subtypes of pulmonary large cell neuroendocrine carcinoma predict chemotherapy treatment outcome. Clin Cancer Res. 2017; 24: 1921.

23. Rieber J, Schmitt J, Warth A, Muley T, Kappes J, Eichhorn F, Hoffmann H, Peter HC, Welzel T, Debus J, Thomas M, Steins M, Rieken S. Outcome and prognostic factors of multimodal therapy for pulmonary large-cell neuroendocrine carcinomas. Eur J Med Res 2015; 20:64.

24. Prelaj A, Rebuzzi S, Del Bene Gabriella, Girón Berríos Julio, Emiliani Alessandra, De Filippis L, Prete Alessandra, Pecorari Silvia, Manna G, Ferrara Carla, Rossini Daniele, Longo Flavia: Evaluation of the efficacy of cisplatin-etoposide and the role of thoracic radiotherapy and prophylactic cranial irradiation in LCNEC. ERJ Open Res. 2017; 3:00128.

25. Mantel N: Evaluation of survival data and two new rank order statistics arising in its consideration. Cancer Chemother Rep. 1966; 50:163-170.

26. Hann CL, Rudin CM: Management of small-cell lung cancer: incremental changes but hope for the future. Oncology (Williston Park). 2008; 22:1486-1492.

27. Derks JL, van Suylen RJ, Thunnissen E, den Bakker MA, Groen HJ, Smit EF, Damhuis RA, van den Broek EC, Speel EM, Dingemans AC: Chemotherapy for pulmonary large cell neuroendocrine carcinomas: does the regimen matter? Eur Respir J. 2017; 49. 